Vol. 1 No. 2, Juli 2021, hlm. 129 - 134

DOI: https://doi.org/10.33330/j-com.v2i1.1226

Available online at http:// jurnal.stmikroyal.ac.id/index.php/j-com

\title{
RANCANG BANGUN ROBOT SAMPAH DENGAN SYSTEM KENDALI ANDROID DAN SYSTEM BUKA WADAH OTOMATIS BERBASIS CONTROLLER
}

\author{
Wahyudi Chandra $^{1}$, Zulfi Azhar ${ }^{2 *}$, Rizky Fauziah ${ }^{2}$ \\ ${ }^{1}$ Mahasiswa Program Studi Sistem Informasi Komputer STMIK Royal \\ ${ }^{2}$ Dosen Program Studi Sistem Informasi, STMIK Royal \\ *email: zulfi_azhar@yahoo.co.id
}

\begin{abstract}
Plastic waste and plastic bottles are also waste that have a very long dissolving period or break down period. Like a cafe or a place to eat on Merbo Bagan Asahan village Tanjung Balai sub-district Asahan district which has about 5 cafes and does not include street vendors. The Asahan area has a population of 118,750 people, assuming the waste product ranges from 356,250 $1 /$ day, and the amount of waste is $160 \mathrm{~m} 3 /$ day. Based on the above problem conditions, making a garbage robot can increase the interest of cafe visitors to dispose of garbage in its place, by utilizing a type of qualitative research method and the results of research testing on the electronics module in the design of a garbage robot found that the interface system between Android and the robot utilizes a 5VDC voltage, with pins RX-TX and TX-RX, as well as all outputs in the form of SG90 servo using 5VDC supply and IC L298 mini supplied with 7.4 VDC voltage. So that one of the advantages of the garbage robot design is that it is able to operate both remotely and in a stopped condition.
\end{abstract}

Keywords: Garbage Robot; Android Control System; Controller Based.

\begin{abstract}
Abstrak: Sampah plastik dan botol plastik juga merupakan sampah yang memiliki masa larut atau masa terurai yang sangat lama. Seperti cafe atau tempat makan yang berada di jalan Merbo Desa Bagan Asahan Kecamatan Tanjung Balai Kabupaten Asahan yang memiliki sekitar 5 cafe dan tidak termasuk pedagang kaki lima. Untuk wilayah Asahan memiliki jumlah penduduk 118.750 jiwa, dengn asumsi produk sampah berkisar $356.250 \mathrm{l} / \mathrm{hr}$, dan jumlah sampah $160 \mathrm{~m}^{3} / \mathrm{hr}$. Berdasarkan kondisi masalah diatas pembuatan robot sampah bisa menambah minat para pengunjung cafe untk membuang sampah pada tempatnya, dengan memanfaatkan jenis metode penelitian kualitatif dan hasil pengujian penelitian pada modul elektronika pada perancangan robot sampah mendapati bahwa sistem interface antara android dengan robot memanfaatkan tegangan 5VDC, dengan pin RX-TX dan TX-RX, serta seluruh output berupa servo SG90 menggunakan supply 5VDC dan IC 1298 mini disupply tegangan 7.4 VDC. Sehingga salah satu kelebihan dari rancangan robot sampah yaitu mampu beroperasi baik dikendalikan jarak jauh ataupun dalam kondisi berhenti.
\end{abstract}

Kata kunci : Robot Sampah;System Kendali Android;Berbasis Controller. 
Vol. 2 No. 1, Juli 2021, hlm. $115-122$

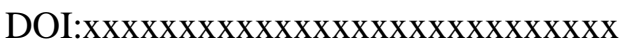

Available online at http:// jurnal.stmikroyal.ac.id/index.php/j-com

\section{PENDAHULUAN}

Sampah plastik dan botol plastik juga merupakan sampah yang memiliki masa larut atau masa terurai yang sangat lama. Seperti cafe atau tempat makan yang berada di jalan Merbo Kabupaten Asahan Kecamatan Tanjung Balai Desa Bagan Asahan yang memiliki sekitar 5 cafe dan tidak termasuk pedagang kaki lima.

Hasil pengamatan dilapangan dan pemilihan objek penelitian diseluruh cafe yang berada di jalan Merbo, didapati bahwa: (1) Lokasi cafe di wilayah Desa Merbo sering dijadikan tempat berkumpulnya remaja dan orang tua serta mulai banyaknya sampah yang diproduksi atau dihasilkan oleh cafe-cafe tersebut, (2) Hampir setiap hari tiap cafe menghasilkan sampah berupa sampah sisa makanan seperti remah kacang atau remah mie instan dan nasi, sampah plastik dari botol minuman dan pembungkus makanan serta sampah cair dari sisa minuman dan sisa kuah, (3) Sampah yang dihasilkan terkadang dibiarkan menumpuk dan terkadang dibuang dibelakang dapur cafe atau selokan, sehingga membuat lingkungan tidak begitu bersih, dan membuat selokan menjadi kotor dan tersumbat.

Berdasarkan pada kondisi di jalan Merbo, Kabupaten Asahan Kecamatan Tanjung Balai, Desa Bagan Asahan, banyaknya volume sampah yang dihasilkan setiap harinya maka peneliti ingin merancang sebuah robot pemungut sampah dengan memanfaatkan system kendali dari android. Robot akan dikendalikan melalui android dengan memanfaatkan koneksi interface dari modul Bluetooth.

\section{METODE}

\section{Motor Servo}

Terdapat 2 tipe motor servo, yaitu servo standard dan servo continuous. Biasanya untuk tipe standard hanya dapat melakukan pergerakan sebesar $180^{\circ}$, sedangkan untuk tipe continuous dapat melakukan rotasi atau $360^{\circ}$.

\section{Arduino Nano}

Papan rangkaian elektronika ataupun Arduino nano merupakan opensource yang ada komponen utama di dalamnya, satu chip mikrokontroler berjenis AVR. Arduino Software (IDE) dapat menghubungkan dengan kabel USB ke personal computer atau laptop [1]. Pada board Arduino Uno mempunyai pin dapat berguna untuk input maupun output. Pin itu dijalankan dengan tegangan 5 volt [2].

\section{Baterai}

Baterai adalah suatu proses kimia listrik, dimana pada saat pengisian energi listrik diubah menjadi kimia dan saat pengeluaran/discharge energi kimia diubah menjadi energi listrik. Baterai menghasilkan listrik melalui proses kimia.

\section{Bluetooth}

Bluetooth adalah protokol komunikasi wireless yang bekerja pada frekuensi radio $2.4 \mathrm{GHz}$ untuk pertukaran data pada perangkat bergerak seperti PDA, laptop, HP, dan lain-lain. Salah satu hasil contoh modul Bluetooth yang paling banyak digunakan 
adalah tipe HC-05. Module Bluetooth HC-05 merupakan module Bluetooth yang bisa menjadi slave ataupun master hal ini dibuktikan dengan bisa memberikan notifikasi untuk melakukan pairing keperangkat lain, maupun perangkat lain tersebut yang melakukan pairing ke module Bluetooth $\mathrm{CH}-05$.

\section{Motor DC}

Motor Listrik DC atau DC Motor adalah suatu perangkat yang mengubah energi listrik menjadi energi kinetik atau gerakan (motion). Motor DC ini juga dapat disebut sebagai Motor Arus Searah. Untuk putaran per menit (Revolutions per minute) pada motor listrik dapat dilakukan berputar searah jarum jam atau sebaliknya, mempunyai berbagai ukuran rpm.

\section{Driver L298d}

L298 adalah jenis IC driver motor yang dapat mengendalikan arah putaran dan kecepatan motor DC ataupun Motor stepper. Mampu mengeluarkan output tegangan untuk Motor DC dan motor stepper sebesar 50 volt. IC 1298 terdiri dari transistortransistor logik (TTL) dengan gerbang NAND yang memudahkan dalam menentukkan arah putaran suatu motor dc dan motor stepper. Prinsip kerja dari IC L298 yaitu berfungsi sebagai pengendali motor. Dalam IC ini juga terdapat dua buah motor.

\section{Ultrasonic SFR -05}

UtrasonicHC-SR04 Adalah modul sensor ultrasonik yang dapat mengukur jarak dengan rentang dari mulai $2 \mathrm{~cm}$ sampai dengan $4 \mathrm{~cm}$, dengan nilai akurasinya mencapai $3 \mathrm{~mm}$. Pada modul ini terdapat ultrasonik transmitter, reveiver dan control circuit.

\section{HASIL PENELITIAN}

Pada tong sampah yang akan dipasangkan modul controller dan beberapa motor DC, sehingga membentuk bagian dari robot sampah dengan sistem kendali dari android menggunakan jenis tong sampah dengan ukuran kecil yang banyak dijual dipasaran. Pada gambar 4.6 dibawah menampilkan desain dari hardware robot sampah yang dilengkapi beberapa modul elektronika dan modul sensor dengan bentuk robot beroda mengikut baris[3]. Penggunaan sensor yang digunakan dalam mendeteksi garis putih di lantai, menggunakan photodioda [4].

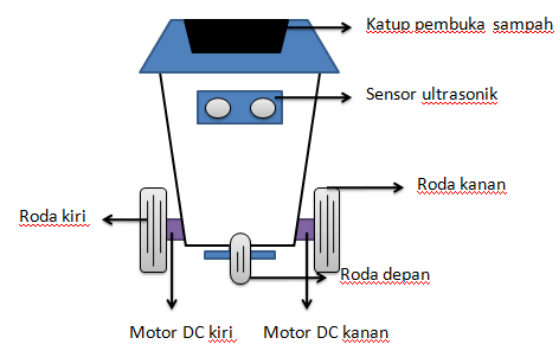

Gambar 1. Tampilan Robot Sampah

Pada gambar diatas menampilkan bahwa, robot sampah yang dirancang menggunakan 2 motor de sebelah kiri dan kanan dan roda bantu untuk menggerakan 
motor, penggunaan sensor ultrasonic yng difungsikan membaca jarak benda atau jarak suatu sampah dengan adanya fitur perintah dengan jalur hitam yang atasnya permukaan putih [5].

\section{Analisis Konfigurasi Sistem}

Tujuan analisis pada penelitian ini untuk mengetahui sirkuit yang benar agar tidak terjadi short atau error compile pada saat pengujian alat. Adapun analisis konfigurasi sistem pada beberapa modul yang digunakan, diantaranya Konfigurasi sistem antara controller dengan servo : (1) Kabel oranye servo dihubungkan kepin 5 controller, (2) Kabel merah servo dihubungkan ke pin vcc controller, (3) Kabel coklat servo dihubungkan ke pin gnd controller.

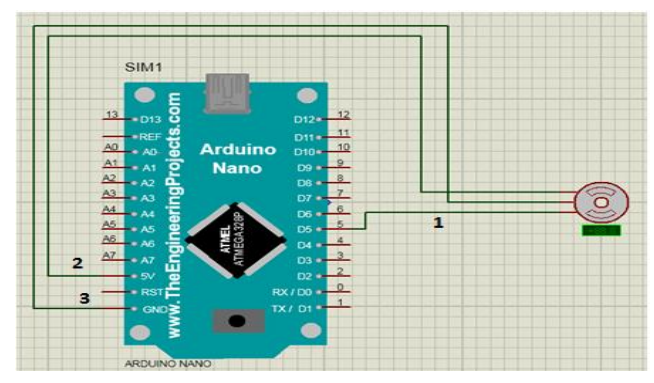

\section{Gambar 2. Scematik Controller Dengan Motor Servo}

Penjelasan pada gambar diatas menjelaskan tentang pengkabelan motor servo yang memiliki 3 kabel dan memiliki fungsi berbeda beda, seperti penjelasan pada rangkaian diatas. Fungsi motor servo pada rangkaian diatas, bertujuan untuk mengubah arah putaran motor servo untuk menggerakan selang motor pompa. Konfigurasi sistem antara controller dengan ic Driver : (1) In1 ic driver dihubungkan ke pin 12 arduino, (2) In 2 ic driver dihubungkan ke pin 11 arduino, (3) In 3 ic driver dihubungkan ke pin 10 arduinio, (4) In 4 ic driver dihubungkan ke pin 9 arduino.

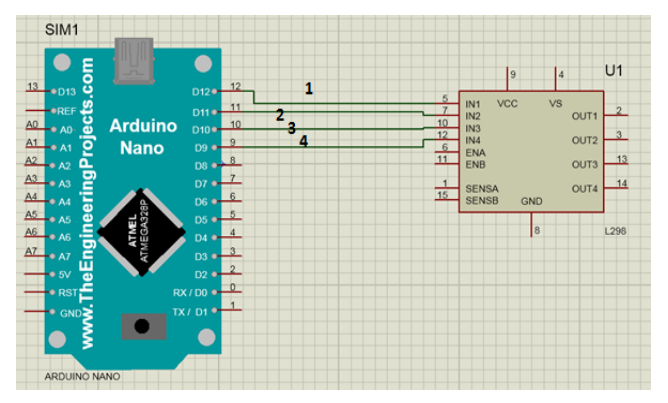

\section{Gambar 3. Scematik Dengan IC Driver}

Berdasarkan pada gambar diatas tentang system pengkabelan IC Driver dengan arduino, dimana in1 dan in3 berfungsi untuk menggerakan motor sebelah kiri searah dengan jarum jam dan sebaliknya, sedangkan in2 dan in4 berfungsi untuk menggerakan motor sebelah kanan, searah jarum jam dan berlawanan jarum jam. Konfigurasi sistem antara controller interface hc-05: (1) Pin rx interface dihubungkan ke pin tx arduino, (2) 
Pin tx interface dihubungkan ke pin $\mathrm{rx}$ arduino, (3) Pin 5v dihubungkan ke pin vcc arduino, (4) Pin gnd dihubungkan ke pin gnd arduino.

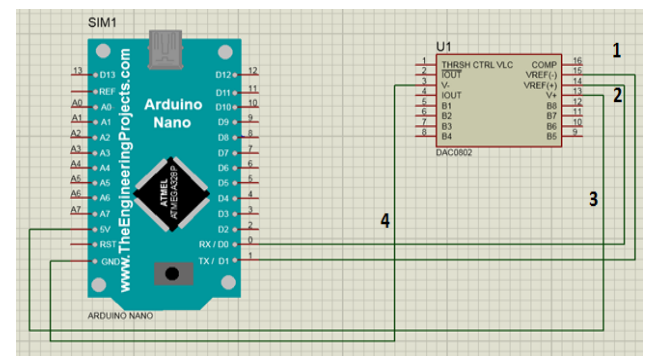

\section{Gambar 4. Scematik Controller Dengan Interface Hc-05}

Penjelasan pada gambar diatas menjelaskan bahwa pin tx (pengirim) interface hc-05 dengan menghubungkannya ke pin rx (penerima) arduino, dan sebaliknya Hal ini dikarenakan agar pengiriman data tidak beradu pada saat pin tx bertemu dengan tx. Sedangkan untuk tegangan kerja interface dihubungkan dengan tegangan 5VDC12VDC. Konfigurasi sistem antara ic driver 1298n dengan motor dc, (1) Kabel merah motor 1 dihubungkan ke pin 1 motor A, (2) Kabel hitam motor 1dihubungkan ke pin 2 motor A, (3) Kabel merah motor 2 dihubungkan ke pin 1 motor B, (4) Kabel hitam motor 2 dihbungkan ke pin 2 motor B.

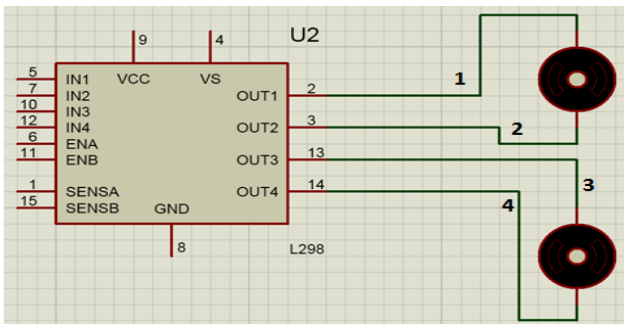

Gambar 5. Scematik Rangkaian Ic Driver Dengan Beban Motor Dc

Penjelasan pada gambar diatas menjelaskan tentang ic driver 1298d dengan keluaran motor DC, dimana motor dc A, terhubung ke output 1 dan output 2, dimana jika output 1 jika diberi data high, maka motor searah dengan arah jarum jam, dan output 2 jika diberi data high, maka motor berlawanan arah jarum jam, begitu juga untuk motor dc B.

\section{Pengujian Robot Sampah di Lapangan}

Pengujian desain rancangan alat dilakukan di Café jalan merbo, desa bagan asahan kecamatan tanjungbalai kabupaten asahan. Pengujian dilakukan dengan cara meletakan robot di tempat sampah semestinya, kemudian menguji coba robot Adapun hasil pengujian robot sampah seperti tabel berikut. 
Vol. 2 No. 1, Juli 2021, hlm. 115 - 122

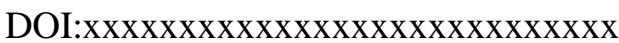

Available online at http:// jurnal.stmikroyal.ac.id/index.php/j-com

Tabel 1. Hasil Pengamatan Pengujian Robot Dilapangan

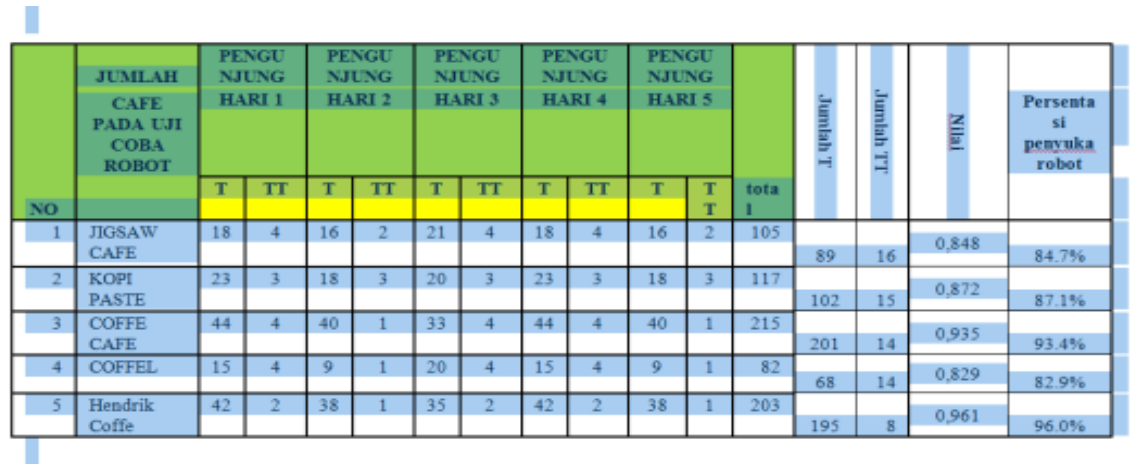

Berdasarkan pada tabel diatas menampilkan dari 5 kafe tersebut, menunjukan lebih dari $82 \%$ pengunjung menyukai robot pemungut sampah dalam membuang sampah pada robot tersebut, selain itu, café Hendrik coffe merupakan café terbanyak yang mendapati jumlah pengunjung yang menyukai membuang sampah di robot.

\section{DAFTAR PUSTAKA}

[1] M. Suari, "Pemanfatan Arduino nano dalam Perancangan Media," Nat. Sci. J., vol. 3, no. 1, pp. 474-480, 2017.

[2] S. Iksal, Suherman, "Perancangan Sistem Kendali Otomatisasi On-Off Lampu Berbasis Arduino dan Borland Delphi," Semin. Nas. Rekayasa Teknol., no. November, pp. 117-123, 2018.

[3] M. Iqbal and S. Solekhan, "Perancangan Wheel Mobile Robot Sebagai Modul Praktikum Mikrokontoler," Simetris J. Tek. Mesin, Elektro dan Ilmu Komput., vol. 4, no. 1, p. 59, 2014, doi: 10.24176/simet.v4i1.125.

[4] E. Safrianti, R. Amri, and S. Budiman, "Prototype Robot Pemadam Api Beroda Menggunakan Teknik Navigasi Wall Follower," J. Rekayasa Elektr., vol. 10, no. 2, 2012, doi: 10.17529/jre.v10i2.134.

[5] S. H. Wahid, A. B. Laksono, and U. Ilmi, "Rancang Bangun Robot Kendali Lingkungan," pp. 53-56. 